\title{
Incidence and outcomes of patients hospitalized with COPD exacerbation with and without pneumonia
}

\author{
Mette Søgaard' \\ Morten Madsen' \\ Anders Løkke ${ }^{2}$ \\ Ole Hilberg ${ }^{2}$ \\ Henrik Toft Sørensen' \\ Reimar W Thomsen' \\ 'Department of Clinical Epidemiology, \\ ${ }^{2}$ Department of Respiratory Medicine, \\ Aarhus University Hospital, Aarhus C, \\ Denmark
}

Correspondence: Mette Søgaard Department of Clinical Epidemiology, Aarhus University Hospital, Olof Palmes Allé 43-45, 8200 Aarhus N, Denmark

Tel +4587168063

Fax +4587167215

Email mso@clin.au.dk
This article was published in the following Dove Press journal:

International Journal of COPD

2 March 2016

Number of times this article has been viewed

Background: Pneumonia may be a major contributor to hospitalizations for chronic obstructive pulmonary disease (COPD) exacerbation and influence their outcomes.

Methods: We examined hospitalization rates, health resource utilization, 30-day mortality, and risk of subsequent hospitalizations for COPD exacerbations with and without pneumonia in Denmark during 2006-2012.

Results: We identified 179,759 hospitalizations for COPD exacerbations, including 52,520 first-time hospitalizations (29.2\%). Pneumonia was frequent in first-time exacerbations $(36.1 \%)$, but declined in successive exacerbations to $25.6 \%$ by the seventh or greater exacerbation. Pneumonic COPD exacerbations increased $20 \%$ from 0.92 per 1,000 population in 2006 to 1.10 per 1,000 population in 2012 . Nonpneumonic exacerbations decreased by $6 \%$ from 1.74 per 1,000 population to 1.63 per 1,000 population during the same period. A number of markers of health resource utilization were more prevalent in pneumonic exacerbations than in nonpneumonic exacerbations: length of stay (median 7 vs 4 days), intensive care unit admission $(7.7 \%$ vs $12.5 \%$ ), and several acute procedures. Thirty-day mortality was $12.1 \%$ in first-time pneumonic COPD exacerbations versus $8.3 \%$ in first-time nonpneumonic cases (adjusted HR [aHR] 1.20, $95 \%$ confidence interval [CI] 1.17-1.24). Pneumonia also predicted increased mortality associated with a second exacerbation (aHR 1.14, 95\% CI 1.11-1.18), and up to a seventh or greater exacerbation (aHR 1.10, 95\% CI 1.07-1.13). In contrast, the aHR of a subsequent exacerbation was $8 \%-13 \%$ lower for patients with pneumonic exacerbations.

Conclusions: Pneumonia is frequent among patients hospitalized for COPD exacerbations and is associated with increased health care utilization and higher mortality. Nonpneumonic COPD exacerbations predict increased risk of subsequent exacerbations.

Keywords: COPD, exacerbation, pneumonia, incidence, mortality

\section{Introduction}

Chronic obstructive pulmonary disease (COPD) is currently the fifth leading cause of death worldwide, and is projected to be the fourth by $2030 .{ }^{1}$ COPD affects $10 \%-20 \%$ of adults aged 40 years and older ${ }^{2-4}$ and is one of the leading causes of hospitalization and high health care costs. ${ }^{5-7}$ Acute exacerbations are responsible for up to $60 \%$ of the costs attributable to $\mathrm{COPD}, 5,8$ and they reduce quality of life $^{9}$ and speed disease progression. ${ }^{10}$

Previous studies have shown that $50 \%-75 \%$ of exacerbations are associated with respiratory infections, ${ }^{11}$ with an unknown proportion associated with pneumonia. Patients with COPD are at greater risk of developing pneumonia than the general population, ${ }^{12-14}$ and COPD is an adverse prognostic factor for patients hospitalized with pneumonia. ${ }^{15}$ However, little is known about the rate of COPD exacerbations with 
and without pneumonia, or about the impact of pneumonia on severity and outcomes of COPD exacerbations. The few previous studies reached conflicting conclusions, showing either no difference in 30-day mortality among patients with nonpneumonic and pneumonic COPD exacerbations ${ }^{16,17}$ or up to $14 \%$ increased in-hospital mortality among patients with pneumonic exacerbations. ${ }^{18,19}$ Pneumonia may worsen the course of COPD exacerbations due to thickening of the blood-gas barrier, leading to pulmonary dysfunction and increased hypoxemia, systemic inflammation, and risk of severe sepsis with hypotension and decreased perfusion of vital organs. Little is known about how pneumonic versus nonpneumonic exacerbations predict the risk of subsequent COPD exacerbations. ${ }^{10}$

The aim of our study was to examine incidence, health resource utilization, 30-day mortality, and risk of new hospitalizations for COPD exacerbation among patients with successive COPD exacerbations with and without pneumonia in Denmark during 2006-2012.

\section{Material and methods}

\section{Setting}

Denmark provides its entire population (5.6 million persons) with tax-supported health care and partial reimbursement for prescribed medications. A unique central personal registration number, assigned to all Danish residents at birth or upon immigration, is used to record health care services in various nationwide registries, allowing unambiguous linkage among registries. ${ }^{20}$ The current nationwide cohort study is based on information from these registries.

\section{Data sources}

The Danish National Patient Registry (DNPR) provides information on all inpatient admissions to hospitals since 1977 , and on all outpatient and emergency room visits since $1995 .^{21}$ For each hospitalization, DNPR files contain data on dates of admission and discharge, surgical procedures performed, if any, and up to 20 discharge diagnoses coded according to the International Classification of Diseases (ICD).

Information on all prescription drugs is maintained in the Danish National Health Service Prescription. ${ }^{22}$ This database records patients' personal identifier, date of dispensing, and type and quantity of drug prescribed (according to the Anatomical Therapeutic Chemical classification system) each time a prescription is redeemed at any Danish pharmacy.

The Danish Civil Registration System (CRS) records information on date of birth, sex, change of address, date of immigration or emigration, and changes in vital status, with daily updates for all individuals legally residing in Denmark at any time since $1968 .{ }^{20}$ The CRS allows for complete follow-up of all residents of Denmark.

All ICD and Anatomical Therapeutic Chemical codes used in this study are provided in the Table S1.

\section{Identification of patients hospitalized for a COPD exacerbation with and without pneumonia}

We used the DNPR to identify all first-time acute inpatient hospitalizations for COPD exacerbations in Denmark between 2006 and 2012. ${ }^{6,23} \mathrm{COPD}$ exacerbation was defined as acute admission with either a primary COPD discharge diagnosis or a primary diagnosis of respiratory tract infection, bronchitis, asthma, acute respiratory distress syndrome, or respiratory failure, combined with a secondary diagnosis of COPD listed during the same admission, or a previous primary diagnosis of COPD present within the preceding 10 years. ${ }^{10}$ We used this expanded definition of COPD exacerbations because restriction to only hospitalizations coded with primary COPD discharge diagnoses results in a documented underreporting of hospitalized COPD exacerbations. ${ }^{23}$ We excluded patients younger than age 40 years at the time of their first COPD hospitalization, given the low COPD prevalence in young people ${ }^{6}$ and the potential risk of misclassification of asthma as COPD.

We categorized all COPD hospitalizations according to whether or not they included a primary or secondary diagnosis of pneumonia.

\section{Data on confounding factors}

We computed Charlson Comorbidity Index (CCI) scores for each patient based on all hospital diagnoses in DNPR records within 10 years preceding the date of the first hospitalization for COPD. ${ }^{24}$ We categorized severity of comorbidity as none (CCI score $=0$ ), medium (CCI score $=1-2$ ), or high (CCI score $\geq 3$ ). ${ }^{25}$ Because alcoholism-related diseases, atrial fibrillation/flutter, asthma, hypertension, osteoporosis, depression, and venous thromboembolism may affect the prognosis of COPD patients and are not included in the CCI, we also identified previous hospitalizations for these conditions. As a marker of social support, we obtained information on marital status (married, never married, divorced, widowed, or unknown) from the $\mathrm{CRS} .{ }^{26}$ To assess the impact of COPD severity, we categorized patients according to their current use of short- and long-acting $\beta$-agonists, inhaled corticosteroids (beclomethasone, mometasone, fluticasone, and budesonide), combinations of inhaled corticosteroids 
and long-acting $\beta$-agonists, and intermittent or continuous use of systemic corticosteroids (Table S1).

\section{Health resource utilization, 30-day mortality, and new exacerbations}

We estimated health resource utilization associated with each exacerbation by length of stay (defined as the difference between admission and discharge dates), admission to an intensive care unit, use of mechanical and noninvasive ventilation, inotropics and dialysis, and all-cause 30-day acute readmissions (defined as any readmission within 30 days following the index discharge). Information on these health resource utilization measures was obtained from the DNRP. Up-to-date information on mortality within 30 days of exacerbation was obtained from the CRS. ${ }^{20}$ Data on new hospitalizations for COPD exacerbations were obtained from the DNRP.

\section{Statistical analysis}

We compared patient characteristics and associated health resource utilization among patients hospitalized for a COPD exacerbation, with and without pneumonia. Descriptive statistics were produced using frequencies, proportions, and prevalence proportion ratios (PPRs) for categorical data, and means, medians, and interquartile ranges (IQR) for continuous variables. We then computed overall rates of first COPD exacerbations, with and without pneumonia, as the number of first exacerbations per year divided by the corresponding midyear population above 40 years in Denmark (obtained from Statistics Denmark).

To examine the risk of 30-day mortality and of a new exacerbation, we followed patients from the date of their first hospitalization for a COPD exacerbation until death from any cause, emigration, or December 31, 2012, whichever came first. To assess the effect of each successive exacerbation on the risk of 30-day mortality, we used Cox regression analysis to compute the hazard ratio (HR) of 30-day mortality comparing COPD patients with and without pneumonic exacerbations. Thus, we assessed the risk of death from the admission date with first exacerbation among all patients with a first exacerbation, from the admission date with second exacerbation among all patients with a second exacerbation, and so forth. Age at first exacerbation, sex, CCI score, and respiratory medications as a marker of COPD severity were included as adjustment factors for the effect of pneumonia. The same Cox regression analysis approach was used to assess the effect of each successive COPD exacerbation on the risk of another hospitalization for an exacerbation during follow-up, considering death a competing risk. ${ }^{27}$ To increase the likelihood of a correct diagnosis of COPD, we conducted a sensitivity analysis in which we excluded all patients with only a diagnosis of simple and mucopurulent chronic bronchitis or chronic bronchitis. Furthermore, because patients with pneumonic COPD exacerbations might be coded as having "COPD with acute lower respiratory infection" rather than pneumonia, we also conducted a sensitivity analysis in which we categorized these patients as having a pneumonic exacerbation.

All statistical analyses were conducted using SAS 9.2 (SAS Institute Inc., Cary, NC, USA). The study was approved by the Danish Data Protection Agency (record no 201241-0793). According to Danish law, use of registry data for research purposes does not require informed consent.

\section{Results Hospitalization rates for COPD exacerbations with and without pneumonia}

We identified 179,759 hospitalizations for COPD exacerbations in Denmark during 2006-2012. Of these, 119,877 (66.7\%) were nonpneumonic and 59,882 (33.3\%) were pneumonic. Among the 52,520 patients with a first-time hospitalization for a COPD exacerbation, 33,552 (63.9\%) had a nonpneumonic exacerbation and 18,968 (36.1\%) had a pneumonic exacerbation. The proportion of patients with pneumonic exacerbations decreased with an increasing number of exacerbations, reaching $25.6 \%$ for seven or more exacerbations (Figure 1). The annual rate of hospitalizations for nonpneumonic exacerbations decreased by $6 \%$ from 1.74 per 1,000 population aged 40 years or older in 2006 to 1.63 per 1,000 population aged 40 years or older in 2012. Concurrently, rates of pneumonic COPD exacerbations increased by $20 \%$, reaching 1.10 per 1,000 population aged 40 years or older in 2012 (Figure 2).

\section{Patient characteristics and health resource utilization}

Characteristics of patients with a first-time hospitalization for a COPD exacerbation are listed in Table 1. Patients with a pneumonic exacerbation had a slightly lower probability than patients with a nonpneumonic exacerbation of receiving any respiratory medication within the 365 days preceding the index admission (72.0\% vs $76.5 \%)$. As well, patients with nonpneumonic exacerbations were more likely than patients with pneumonic exacerbations to use oral corticosteroids 


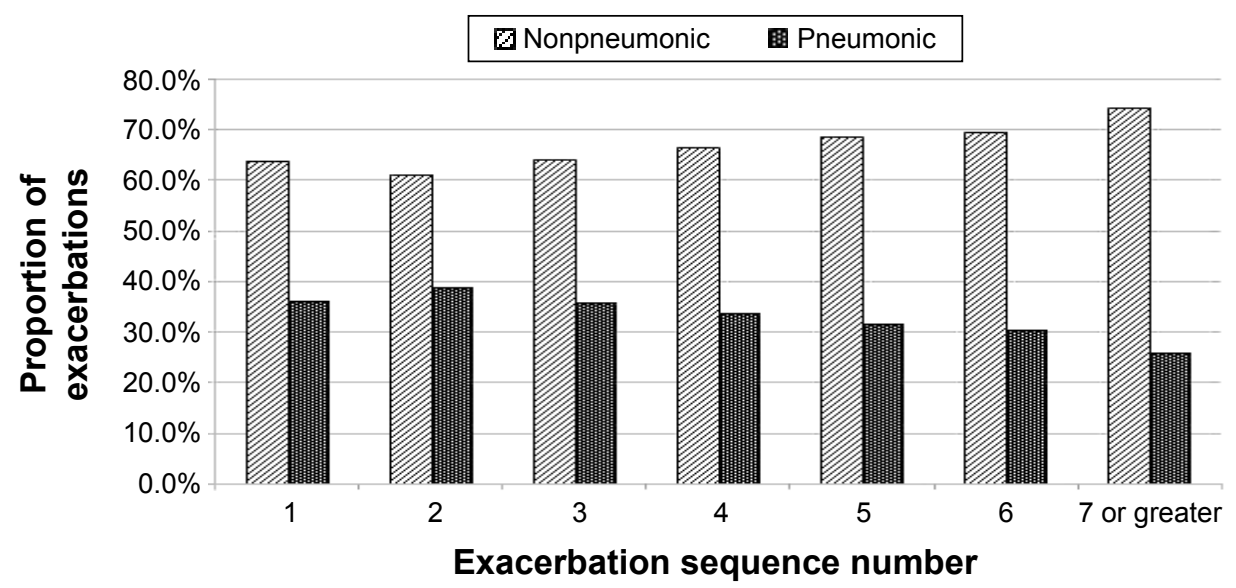

Figure I Proportion of pneumonic and nonpneumonic COPD exacerbations according to number of exacerbations, Denmark, 2006-20I2. Abbreviation: COPD, chronic obstructive pulmonary disease.

(26.8\% vs 20.7\%). Patients with a first-time pneumonic exacerbation were slightly older (median age 75 years, IQR 66-82 years) than patients with a nonpneumonic exacerbation (median age 73 years, IQR 64-80 years), and had a higher prevalence of virtually all comorbidities included in the analysis (57.4\% had a CCI score $\geq 1$ compared with 50.7\% of patients with nonpneumonic exacerbations) (Figure 3).

Table 2 shows the health resource utilization associated with first-time COPD exacerbations. The median length of hospital stay was 4 days (IQR 2-8 days) for patients with a nonpneumonic exacerbation and 7 days (IQR 4-11 days) for patients with a pneumonic exacerbation. Mechanical or noninvasive ventilation was provided to $3.3 \%$ and $6.7 \%$ of patients with nonpneumonic exacerbations respectively, compared with $6.9 \%$ and $9.7 \%$ of patients with pneumonic exacerbations. Patients with pneumonic exacerbations were also more likely to receive inotropic therapy (PPR 2.15, 95\% confidence interval [CI] 1.94-2.37) or dialysis (PPR $1.74,95 \%$ CI 1.39-2.17), and were slightly more likely to be readmitted for any cause within 30 days following discharge (PPR 1.04, 95\% CI 1.00-1.08) compared with patients with nonpneumonic exacerbations (Table 2).

\section{Thirty-day mortality}

Thirty-day mortality was $12.1 \%$ in patients with a first-time pneumonic exacerbation and $8.4 \%$ in those with a first-time

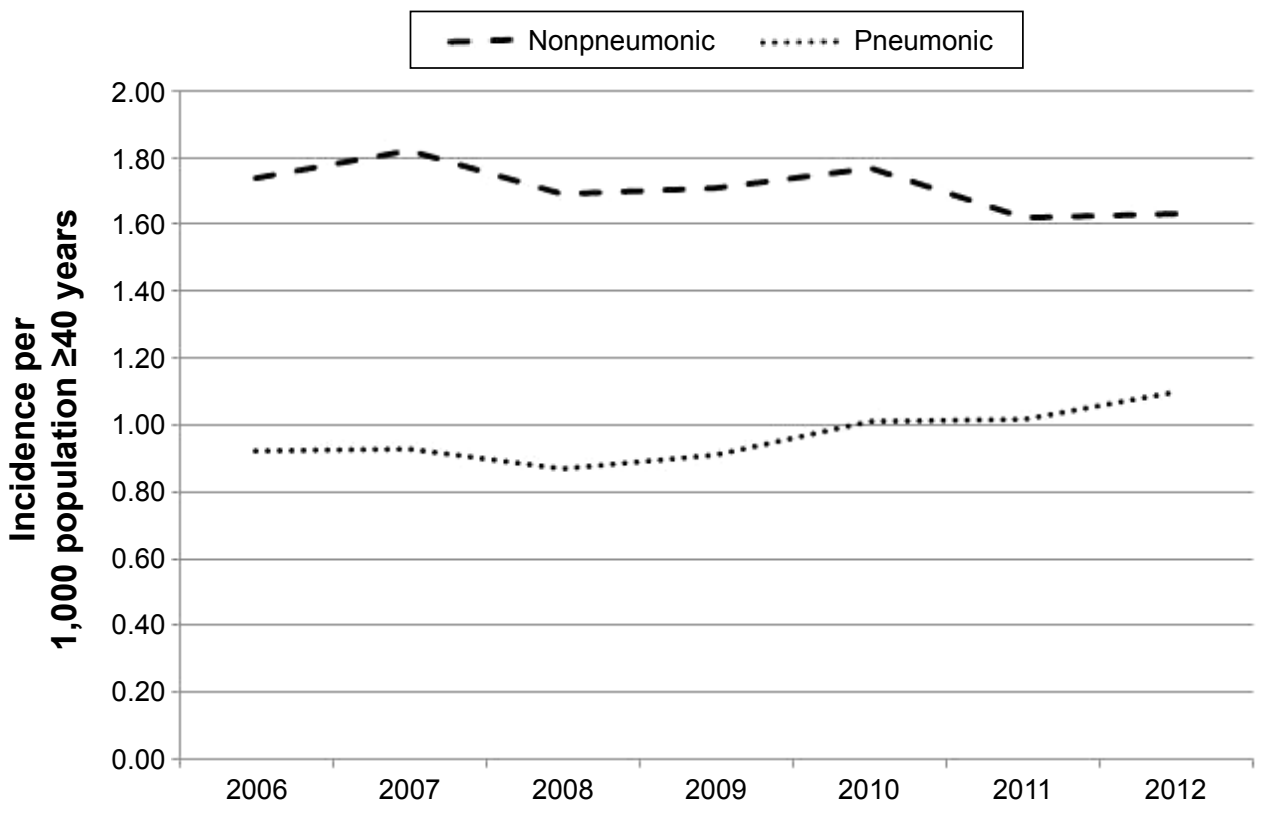

Figure 2 Incidence rates of pneumonic and nonpneumonic COPD exacerbations in individuals aged 40 years and older in Denmark, 2006-20I2. Abbreviation: COPD, chronic obstructive pulmonary disease. 
Table I Baseline characteristics of patients with a first-time hospitalization for a COPD exacerbation in Denmark, 2006-20I2

\begin{tabular}{|c|c|c|c|c|}
\hline \multirow[t]{3}{*}{ Characteristic } & \multicolumn{4}{|c|}{ Exacerbation type } \\
\hline & \multicolumn{2}{|c|}{$\begin{array}{l}\text { Nonpneumonic } \\
\text { exacerbation }\end{array}$} & \multicolumn{2}{|c|}{$\begin{array}{l}\text { Pneumonic } \\
\text { exacerbation }\end{array}$} \\
\hline & No & $\%$ & No & $\%$ \\
\hline Overall & 33,552 & 100 & 18,968 & 100 \\
\hline \multicolumn{5}{|l|}{ Respiratory medications in the year prior to first hospitalization } \\
\hline No respiratory medication use & 7,897 & 23.5 & 5,309 & 28.0 \\
\hline Use of respiratory medications other than inhaled corticosteroids & 11,030 & 32.9 & 6,592 & 34.8 \\
\hline Use of inhaled corticosteroids & 3,388 & 10.1 & 1,788 & 9.4 \\
\hline Use of oral corticosteroids & 8,979 & 26.8 & 3,917 & 20.7 \\
\hline Continuous use of oral corticosteroids & 2,258 & 6.7 & 1,362 & 7.2 \\
\hline \multicolumn{5}{|l|}{ Sex } \\
\hline Female & 18,400 & 54.8 & $9,4 \mathrm{II}$ & 49.6 \\
\hline Male & 15,152 & 45.2 & 9,557 & 50.4 \\
\hline \multicolumn{5}{|l|}{ Age, years } \\
\hline $40-49$ & 1,538 & 4.6 & 552 & 2.9 \\
\hline $50-59$ & 4,036 & 12.0 & $\mathrm{I}, 792$ & 9.4 \\
\hline $60-69$ & 7,954 & 23.7 & 4,125 & 21.7 \\
\hline 70-79 & 11,247 & 33.5 & 6,421 & 33.9 \\
\hline $80-89$ & 7,789 & 23.2 & 5,291 & 27.9 \\
\hline 90 and older & 988 & 2.9 & 787 & 4.1 \\
\hline \multicolumn{5}{|l|}{ Marital status } \\
\hline Married & $|3,28|$ & 42.3 & 7,336 & 42.6 \\
\hline Widowed & 9,841 & 29.3 & 5,765 & 30.4 \\
\hline Divorced & 6,472 & 19.3 & 3,338 & 17.6 \\
\hline Unmarried & I,779 & 5.3 & 857 & 4.5 \\
\hline Unknown & 1,143 & 3.4 & 794 & 4.2 \\
\hline \multicolumn{5}{|l|}{$\mathrm{CCl}$ score } \\
\hline 0 & 16,527 & 49.3 & 8,083 & 42.6 \\
\hline I & 6,811 & 20.3 & 4,077 & 21.5 \\
\hline 2 & 5,067 & 15.1 & 3,146 & 16.6 \\
\hline$\geq 3$ & 5,147 & 15.3 & 3,662 & 19.3 \\
\hline
\end{tabular}

Abbreviations: $\mathrm{CCl}$, Charlson Comorbidity Index; COPD, chronic obstructive pulmonary disease.

nonpneumonic exacerbation, equivalent to an adjusted HR (aHR) of 1.21 (95\% CI 1.17-1.24) after adjusting for age, sex, comorbidity, and respiratory medications (Table 3). Presence of pneumonia also predicted increased mortality among patients hospitalized with a second exacerbation (aHR 1.14, 95\% CI 1.11-1.18), and up to the seventh and subsequent exacerbation (aHR 1.10, 95\% CI 1.07-1.13).

Among patients with a pneumonic COPD exacerbation, $37.3 \%$ had at least one subsequent severe exacerbation requiring hospitalization during median follow-up of 203 days, compared with $43.4 \%$ of patients with a nonpneumonic exacerbation during median follow-up of 213 days (Table 4). After taking into account death as a competing risk, the corresponding aHR of a subsequent hospitalization for an exacerbation associated with pneumonia was 0.93 (95\% CI 0.91-0.96). The time span between successive exacerbations diminished with increasing number of exacerbations, both for pneumonic and nonpneumonic exacerbations. Nonetheless, the aHR of a subsequent exacerbation was $8 \%-13 \%$ lower for patients with pneumonic versus nonpneumonic exacerbations across numbers of exacerbations.

In the sensitivity analysis excluding patients with bronchitis, presence of pneumonia remained consistently associated with increased risk of death and lower risk of a subsequent exacerbation across numbers of exacerbations (data not shown). At their first-time hospitalization for a COPD exacerbation, $9.5 \%$ of patients had a diagnosis of "COPD with acute lower respiratory infection." Categorizing these patients as having pneumonic exacerbations attenuated the difference between pneumonic and nonpneumonic COPD exacerbations (Table S2).

\section{Discussion}

This nationwide population-based cohort study showed a large and apparently increasing burden of pneumonic COPD exacerbations. Approximately $36 \%$ of patients hospitalized for a first-time exacerbation also received a pneumonia diagnosis. During 2006-2012, the incidence of first-time 


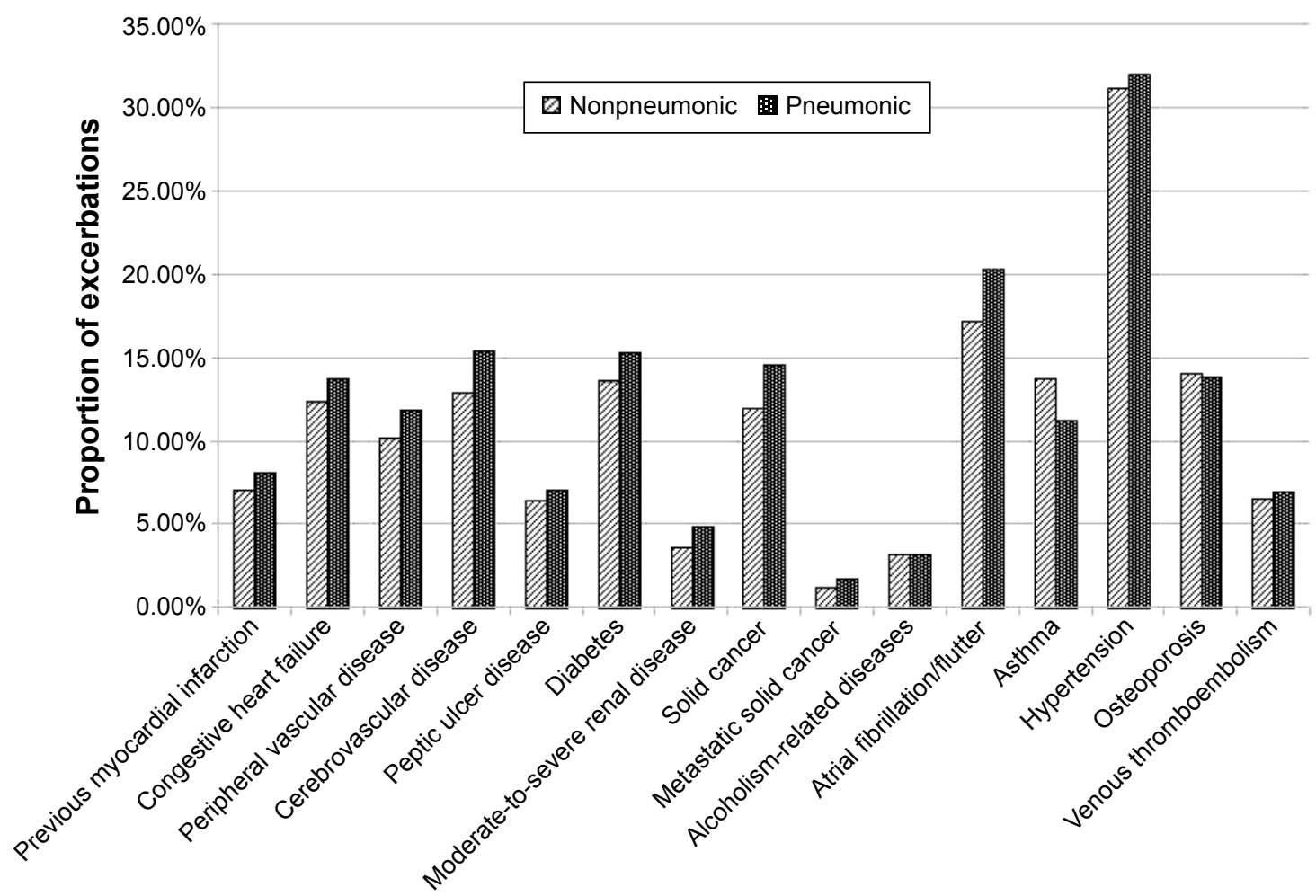

Figure 3 Proportion of comorbidities in patients with pneumonic and nonpneumonic COPD exacerbations, Denmark, $2006-2012$.

Abbreviation: COPD, chronic obstructive pulmonary disease.

hospitalizations for pneumonic exacerbations increased by $20 \%$. Over the same period, the rate of nonpneumonic exacerbations decreased by $6 \%$. Patients with pneumonic exacerbations were older, had more comorbidity, and required more health resources in terms of a prolonged hospital stay, increased use of intensive care, assisted ventilation, inotropic therapy, dialysis, and readmission. Pneumonic exacerbations were also associated with higher 30-day mortality compared with nonpneumonic exacerbations, both in first-time and successive exacerbations, and after adjustment for age, sex, comorbidity, and COPD severity. At the same time, patients with nonpneumonic COPD exacerbations had a slightly higher risk of subsequent hospitalizations for exacerbations than patients with pneumonic exacerbations, regardless of number of exacerbations.

The paucity of data on pneumonic versus nonpneumonic exacerbations to some extent may stem from controversy as to whether or not a case of manifest pneumonia should be

Table 2 Health resource utilization among patients with a first-time nonpneumonic or pneumonic COPD exacerbation, Denmark 2006-2012

\begin{tabular}{|c|c|c|c|}
\hline \multirow[t]{2}{*}{ Health resource utilization } & \multicolumn{2}{|c|}{ Exacerbation type } & \multirow{2}{*}{$\begin{array}{l}\text { Prevalence proportion ratio } \\
\text { pneumonic vs nonpneumonic }(95 \% \mathrm{Cl})\end{array}$} \\
\hline & Nonpneumonic & Pneumonic & \\
\hline Median LOS (IQR), days & $4(2-8)$ & $7(4-I I)$ & - \\
\hline \multicolumn{4}{|l|}{ ICU stay } \\
\hline $\mathrm{N}(\%)$ & $2,585(7.7)$ & $2,373(12.5)$ & $1.63(1.54-1.71)$ \\
\hline \multicolumn{4}{|l|}{ Mechanical ventilation } \\
\hline$N(\%)$ & $1,106(3.3)$ & $1,315(6.9)$ & $2.10(1.95-2.27)$ \\
\hline \multicolumn{4}{|l|}{ Noninvasive mechanical ventilation } \\
\hline$N(\%)$ & $2,240(6.7)$ & I,84I (9.7) & $1.45(1.37-1.54)$ \\
\hline \multicolumn{4}{|l|}{ Inotropic use } \\
\hline$N(\%)$ & $756(2.3)$ & $920(4.9)$ & $2.15(1.94-2.37)$ \\
\hline \multicolumn{4}{|l|}{ Dialysis } \\
\hline $\mathrm{N}(\%)$ & $157(0.5)$ & $154(0.8)$ & $1.74(1.39-2.17)$ \\
\hline \multicolumn{4}{|c|}{ 30-day acute readmission of any cause } \\
\hline $\mathrm{N}(\%)$ & $5,886(17.5)$ & $3,453(\mid 8.2)$ & $1.04(1.00-1.08)$ \\
\hline
\end{tabular}

Abbreviations: $\mathrm{Cl}$, confidence interval; COPD, chronic obstructive pulmonary disease; ICU, intensive care unit; IQR, interquartile range; LOS, length of stay. 
Table 3 Crude and adjusted risk of 30-day mortality according to number of exacerbation ${ }^{\text {a }}$

\begin{tabular}{|c|c|c|c|c|c|}
\hline $\begin{array}{l}\text { Exacerbation } \\
\text { number }\end{array}$ & $\begin{array}{l}\text { Exacerbation } \\
\text { type }\end{array}$ & Patients, $\mathbf{N}$ & $\begin{array}{l}\text { 30-day } \\
\text { mortality (\%) }\end{array}$ & $\begin{array}{l}\text { Crude HR } \\
(95 \% \mathrm{Cl})\end{array}$ & $\begin{array}{l}\text { Adjusted } \mathbf{H R}^{\mathrm{b}} \\
(95 \% \mathrm{Cl})\end{array}$ \\
\hline \multirow[t]{2}{*}{ First } & Nonpneumonic & 33,552 & 8.3 & I (reference) & I (reference) \\
\hline & Pneumonic & 18,968 & 12.1 & $1.35(1.31-1.39)$ & $1.20(1.17-1.24)$ \\
\hline \multirow[t]{2}{*}{ Second } & Nonpneumonic & 18,774 & 10.2 & I (reference) & I (reference) \\
\hline & Pneumonic & 11,878 & 15.0 & $1.33(1.29-1.38)$ & $1.14(1.11-1.18)$ \\
\hline \multirow[t]{2}{*}{ Third } & Nonpneumonic & 13,173 & 10.4 & I (reference) & I (reference) \\
\hline & Pneumonic & 7,356 & 15.2 & $1.27(1.22-1.32)$ & $1.12(1.08-1.17)$ \\
\hline \multirow[t]{2}{*}{ Fourth } & Nonpneumonic & 9,727 & 10.5 & I (reference) & I (reference) \\
\hline & Pneumonic & 4,907 & 13.5 & $1.20(1.15-1.26)$ & $1.08(1.03-1.14)$ \\
\hline \multirow[t]{2}{*}{ Fifth } & Nonpneumonic & 7,524 & 10.4 & I (reference) & I (reference) \\
\hline & Pneumonic & 3,450 & 14.1 & $1.22(1.16-1.29)$ & $1.10(1.04-1.16)$ \\
\hline \multirow[t]{2}{*}{ Sixth } & Nonpneumonic & 5,873 & 10.1 & I (reference) & I (reference) \\
\hline & Pneumonic & 2,553 & 13.3 & $1.19(1.12-1.27)$ & $1.12(1.06-1.19)$ \\
\hline \multirow[t]{2}{*}{ Seventh or greater } & Nonpneumonic & 31,254 & 8.9 & I (reference) & I (reference) \\
\hline & Pneumonic & 10,770 & 11.3 & $1.17(1.13-1.20)$ & $1.10(1.07-1.13)$ \\
\hline
\end{tabular}

Notes: aRisk of death is assessed from the admission date with first exacerbation among all patients with a first exacerbation, from the admission date with second exacerbation among all patients who have a second exacerbation, and so forth. ${ }^{b}$ Adjusted for age, sex, CCI score, and respiratory medications as a marker of COPD severity.

Abbreviations: $\mathrm{CCl}$, Charlson Comorbidity Index; $\mathrm{Cl}$, confidence interval; COPD, chronic obstructive pulmonary disease; HR, hazard ratio.

considered as part of a COPD exacerbation. Some consider pneumonia and acute exacerbations in COPD patients as separate acute events. ${ }^{16,28}$ Still, the British Thoracic Society includes COPD patients with X-ray-confirmed pneumonia in their national audit of COPD exacerbations. ${ }^{19}$ The Global Initiative for Chronic Obstructive Lung Disease defines an exacerbation as an event in the clinical course of COPD characterized by amplification of the state of chronic inflammation in the airways and acute onset of aggravation of baseline symptoms beyond normal day-to-day variations and leading to a change in medication..$^{29}$ This broad definition may include a wide range of manifestations, including those of pneumonia. ${ }^{30}$ Accordingly, in this study, we considered hospitalization for pneumonia to be a COPD exacerbation.

Compared with the few previous studies, ${ }^{17-19,31}$ we identified a relatively high proportion of patients with a first-time pneumonic COPD exacerbation. In a recent Norwegian study of 1,144 patients hospitalized with COPD exacerbations, 237 (20.7\%) had pneumonia defined as a pneumonic infiltrate on X-ray and CRP equal to or above $40 \mathrm{mg} / \mathrm{L} .{ }^{17} \mathrm{In}$ the 2008 National UK COPD audit, 16\% of patients hospitalized with a COPD exacerbation presented with radiographic

Table 4 Crude and adjusted risk of a subsequent exacerbation according to number of exacerbation ${ }^{\mathrm{a}}$

\begin{tabular}{|c|c|c|c|c|c|c|}
\hline $\begin{array}{l}\text { Exacerbation } \\
\text { number }\end{array}$ & $\begin{array}{l}\text { Exacerbation } \\
\text { type }\end{array}$ & $\begin{array}{l}\text { Patients with } \\
\text { exacerbation, } \mathbf{N}\end{array}$ & $\begin{array}{l}\text { Proportion with } \\
\text { a subsequent } \\
\text { exacerbation (\%) }\end{array}$ & $\begin{array}{l}\text { Median time } \\
\text { to subsequent } \\
\text { exacerbation (days) }\end{array}$ & $\begin{array}{l}\text { Crude HR } \\
(95 \% \mathrm{Cl})\end{array}$ & $\begin{array}{l}\text { Adjusted } \mathrm{HR}^{\mathrm{b}} \\
(95 \% \mathrm{Cl})\end{array}$ \\
\hline \multirow[t]{2}{*}{ First } & Pneumonic & 14,560 & 43.4 & 213 & I (reference) & I (reference) \\
\hline & Nonpneumonic & 7,073 & 37.3 & 206 & $0.94(0.92-0.97)$ & $0.93(0.91-0.96)$ \\
\hline \multirow[t]{2}{*}{ Second } & Pneumonic & 10,949 & 58.3 & 142 & I (reference) & I (reference) \\
\hline & Nonpneumonic & 5,786 & 48.7 & 146 & $0.87(0.85-0.90)$ & $0.88(0.85-0.91)$ \\
\hline \multirow[t]{2}{*}{ Third } & Pneumonic & 8,581 & 65.1 & 106 & I (reference) & I (reference) \\
\hline & Nonpneumonic & $4,13 \mid$ & 56.2 & 120 & $0.90(0.86-0.93)$ & $0.92(0.88-0.95)$ \\
\hline \multirow[t]{2}{*}{ Fourth } & Pneumonic & 6,838 & 70.3 & 83 & I (reference) & I (reference) \\
\hline & Nonpneumonic & 3,016 & 61.5 & 97 & $0.86(0.82-0.90)$ & $0.87(0.84-0.91)$ \\
\hline \multirow[t]{2}{*}{ Fifth } & Pneumonic & 5,433 & 72.2 & 75 & I (reference) & I (reference) \\
\hline & Nonpneumonic & 2,223 & 64.4 & 86 & $0.90(0.85-0.94)$ & $0.91(0.86-0.95)$ \\
\hline \multirow[t]{2}{*}{ Sixth } & Pneumonic & 4,405 & 75.0 & 66 & I (reference) & I (reference) \\
\hline & Nonpneumonic & $\mathrm{I}, 739$ & 68.1 & 74 & $0.93(0.88-0.98)$ & $0.94(0.89-1.00)$ \\
\hline \multirow[t]{2}{*}{ Seventh or greater } & Pneumonic & 25,839 & 82.7 & 38 & I (reference) & I (reference) \\
\hline & Nonpneumonic & 8,151 & 75.7 & 48 & $0.86(0.84-0.89)$ & $0.88(0.86-0.90)$ \\
\hline
\end{tabular}

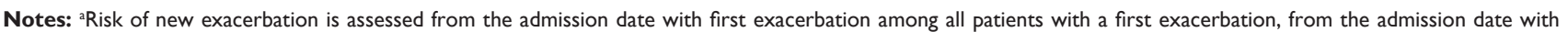

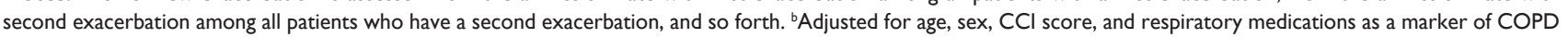
severity.

Abbreviations: $\mathrm{CCl}$, Charlson Comorbidity Index; $\mathrm{Cl}$, confidence interval; COPD, chronic obstructive pulmonary disease; HR, hazard ratio. 
consolidation. ${ }^{19}$ In another study, 23 (9\%) patients among 250 patients hospitalized for acute exacerbation had X-ray findings indicating pneumonia. ${ }^{31}$ In contrast with our study, these studies focused on prevalent rather than incident episodes. We showed that the proportion of pneumonic exacerbations declined with the number of exacerbations, which explains part of the differences in findings. In their study, Steer et al ${ }^{18}$ included patients with a first-time hospitalization for a COPD exacerbation and found that 299 (33\%) of 920 patients were categorized with pneumonic exacerbations based on X-ray findings. This is in line with our finding that $36 \%$ of patients in our study who presented with a first-time COPD exacerbation had pneumonia. Also corroborating our findings, earlier studies reported that patients with pneumonic exacerbations tend to be older, have more comorbidity, a longer length of stay, and more assisted ventilation compared with patients with nonpneumonic exacerbations. ${ }^{17-19}$

In line with the findings of Suissa et al, ${ }^{10}$ we observed that severe exacerbations appeared to recur progressively sooner after each subsequent severe exacerbation. The reason for the apparently higher risk of subsequent exacerbations among those with nonpneumonic exacerbations is not clear, but might be related to a phenotype associated with persistent and increased propensity for airway and systemic inflammation ${ }^{32}$ without a propensity for manifest respiratory tract infection. Another explanation may be more intensive antibiotic therapy given to patients with manifest pneumonia, including possible prophylactic use of azithromycin in some patients, which may prevent or delay new COPD exacerbations..$^{33,34}$ Use of inhaled corticosteroids has been associated with decreased risk of subsequent exacerbations and increased risk for hospitalization with pneumonia. ${ }^{35}$ However, prior use of inhaled corticosteroids differed little among nonpneumonic and pneumonic first-time admitted patients in our study, and therefore also was unlikely to explain any observed differences in mortality. ${ }^{36}$ To some extent, the higher risk of subsequent exacerbation in patients following nonpneumonic exacerbations may have been related to the higher mortality during index admission in those with pneumonic exacerbation, leaving fewer frail patients at risk of subsequent exacerbations (depletion of susceptibles).

Our estimates of COPD exacerbation and mortality are based on a nationwide cohort study conducted in a setting in which a national health service provides unfettered access to health care, thus largely eliminating referral and diagnostic biases. Our study included the entire Danish population and had complete follow-up through the use of nationwide registries, so it also avoided the selection biases hampering clinic-based studies.

Our study also has limitations. It is important to note that our results focused only on COPD exacerbations requiring hospitalization. As well, the accuracy of diagnoses of pneumonic and nonpneumonic COPD exacerbation were dependent on proper ICD-10 coding. Previous DNRP validation studies have revealed positive predictive value $92 \%-100 \%$ of ICD codes for primary COPD ${ }^{25}$ and COPD exacerbations. ${ }^{23}$ Our data had similarly high accuracy for detecting pneumonia requiring hospitalization (ie, a predictive value of $\sim 90 \%)^{37,38}$ and for the comorbid conditions in the CCI. ${ }^{25}$ The validity of pneumonia codes associated with COPD has not been well studied. The decline in the proportion of exacerbations with pneumonia over subsequent episodes may suggest that the likelihood of actually having COPD increases with each episode. However, any misclassification between pneumonic and nonpneumonic episodes would tend to diminish observed differences between the two conditions, not changing our conclusions. Another limitation is the lack of clinical data on the length of each exacerbation, making it difficult to differentiate between relapse and recurrence..$^{10,39,40}$ However, the majority of patients recover within 30 days after the onset of a COPD exacerbation. ${ }^{40}$ In our data, the median time between hospitalizations ranged from 38 to 213 days, supporting the conclusion that they are in fact recurrent events. We also lacked clinical data on severity of symptoms, airflow limitations, and exercise intolerance, and lifestyle factors such as poor nutrition, alcohol consumption, and tobacco smoking that may influence prognosis. ${ }^{41}$ However, we were able to control for hospital diagnoses of alcohol-related conditions and many other lifestyle-related diseases including diabetes, cardiovascular disease, and cancer.

We conclude that pneumonia is common in patients hospitalized with acute COPD exacerbations and is associated with increased health resource utilization and poor prognosis compared with patients with nonpneumonic exacerbations. Our results emphasize the need for increased attention to treatment and prevention of pneumonia in patients with COPD.

\section{Acknowledgment}

This study was partly supported by a research grant from Pfizer A/S to Aarhus University.

\section{Disclosure}

The authors report no conflicts of interest in this work. 


\section{References}

1. Mathers CD, Loncar D. Projections of global mortality and burden of disease from 2002 to 2030. PLoS Med. 2006;3(11):e442.

2. Gershon AS, Warner L, Cascagnette P, Victor JC, To T. Lifetime risk of developing chronic obstructive pulmonary disease: a longitudinal population study. Lancet. 2011;378(9795):991-996.

3. Buist AS, McBurnie MA, Vollmer WM, et al. International variation in the prevalence of COPD (the BOLD Study): a population-based prevalence study. Lancet. 2007;370(9589):741-750.

4. Fabricius P, Løkke A, Louis J, Vestbo J, Lange P. Prevalence of COPD in Copenhagen. Respir Med. 2011;105(3):410-417.

5. Bilde L, Rud Svenning A, Dollerup J, Baekke Borgeskov H, Lange P. The cost of treating patients with COPD in Denmark - a population study of COPD patients compared with non-COPD controls. Respir Med. 2007;101(3):539-546.

6. Lash TL, Johansen MB, Christensen S, et al. Hospitalization rates and survival associated with COPD: a nationwide Danish cohort study. Lung. 2011;189(1):27-35.

7. Løkke A, Hilberg O, Tønnesen P, Ibsen R, Kjellberg J, Jennum P. Direct and indirect economic and health consequences of COPD in Denmark: a national register-based study: 1998-2010. BMJ Open. 2014;4(1):e004069.

8. Pasquale MK, Sun SX, Song F, Hartnett HJ, Stemkowski SA. Impact of exacerbations on health care cost and resource utilization in chronic obstructive pulmonary disease patients with chronic bronchitis from a predominantly Medicare population. Int J Chron Obstruct Pulmon Dis. 2012;7:757-764.

9. Doll H, Miravitlles M. Health-related QOL in acute exacerbations of chronic bronchitis and chronic obstructive pulmonary disease: a review of the literature. Pharmacoeconomics. 2005;23(4):345-363.

10. Suissa S, Dell'Aniello S, Ernst P. Long-term natural history of chronic obstructive pulmonary disease: severe exacerbations and mortality. Thorax. 2012;67(11):957-963.

11. Sapey E, Stockley RA. COPD exacerbations. 2: aetiology. Thorax. 2006; 61(3):250-258.

12. Müllerova $\mathrm{H}$, Chigbo $\mathrm{C}$, Hagan $\mathrm{GW}$, et al. The natural history of community-acquired pneumonia in COPD patients: a population database analysis. Respir Med. 2012;106(8):1124-1133.

13. Benfield T, Lange P, Vestbo J. COPD stage and risk of hospitalization for infectious disease. Chest. 2008;134(1):46-53.

14. Ryan M, Suaya JA, Chapman JD, Stason WB, Shepard DS, Thomas CP Incidence and cost of pneumonia in older adults with COPD in the United States. PLoS One. 2013;8(10):e75887.

15. Molinos L, Clemente MG, Miranda B, et al. Community-acquired pneumonia in patients with and without chronic obstructive pulmonary disease. J Infect. 2009;58(6):417-424

16. Huerta A, Crisafulli E, Menéndez R, et al. Pneumonic and nonpneumonic exacerbations of COPD: inflammatory response and clinical characteristics. Chest. 2013;144(4):1134-1142.

17. Andreassen SL, Liaaen ED, Stenfors N, Henriksen AH. Impact of pneumonia on hospitalizations due to acute exacerbations of COPD. Clin Respir J. 2014;8(1):93-99.

18. Steer J, Norman EM, Afolabi OA, Gibson GJ, Bourke SC. Dyspnoea severity and pneumonia as predictors of in-hospital mortality and early readmission in acute exacerbations of COPD. Thorax. 2012;67(2): 117-121.

19. Myint PK, Lowe D, Stone RA, Buckingham RJ, Roberts CM. UK National COPD Resources and Outcomes Project 2008: patients with chronic obstructive pulmonary disease exacerbations who present with radiological pneumonia have worse outcome compared to those with non-pneumonic chronic obstructive pulmonary disease. Respiration. 2011;82(4):320-327.

20. Schmidt M, Pedersen L, Sørensen HT. The Danish Civil Registration System as a tool in epidemiology. Eur J Epidemiol. 2014;29(8): $541-549$.
21. Lynge E, Sandegaard JL, Rebolj M. The Danish National Patient Register. Scand J Public Health. 2011;39(7 Suppl):30-33.

22. Johannesdottir SA, Horváth-PuhóE, Ehrenstein V, Schmidt M, Pedersen L, Sørensen HT. Existing data sources for clinical epidemiology: the Danish National database of reimbursed prescriptions. Clin Epidemiol. 2012;4(1):303-313.

23. Thomsen RW, Lange P, Hellquist B, et al. Validity and underrecording of diagnosis of COPD in the Danish National Patient Registry. Respir Med. 2011;105(7):1063-1068.

24. Charlson ME, Pompei P, Ales KL, MacKenzie CR. A new method of classifying prognostic comorbidity in longitudinal studies: development and validation. J Chronic Dis. 1987;40(5):373-383.

25. Thygesen SK, Christiansen CF, Christensen S, Lash TL, Sørensen HT. The predictive value of ICD-10 diagnostic coding used to assess Charlson comorbidity index conditions in the population-based Danish National Registry of Patients. BMC Med Res Methodol. 2011; 11(1):83

26. Mor A, Ulrichsen SP, Svensson E, Berencsi K, Thomsen RW. Does marriage protect against hospitalization with pneumonia? A populationbased case-control study. Clin Epidemiol. 2013;5:397-405.

27. Andersen PK, Geskus RB, de Witte T, Putter H. Competing risks in epidemiology: possibilities and pitfalls. Int J Epidemiol. 2012;41(3): 861-870.

28. Calverley PM, Stockley RA, Seemungal TA, et al. Reported pneumonia in patients with COPD: findings from the INSPIRE study. Chest. 2011;139(3):505-512.

29. The Global Strategy for the Diagnosis, Management and Prevention of COPD, Global Initiative for Chronic Obstructive Lung Disease (GOLD) 2015. 2015. Available from: http://www.goldcopd.org/. Accessed August 6, 2015.

30. Wackerhausen LH, Hansen JG. Risk of infectious diseases in patients with COPD. Open Infect Dis J. 2012;6:52-59.

31. Lieberman D, Lieberman D, Gelfer Y, et al. Pneumonic vs nonpneumonic acute exacerbations of COPD. Chest. 2002;122(4):1264-1270.

32. Wedzicha JA, Brill SE, Allinson JP, Donaldson GC. Mechanisms and impact of the frequent exacerbator phenotype in chronic obstructive pulmonary disease. BMC Med. 2013;11(1):1.

33. Herath SC, Poole P. Prophylactic antibiotic therapy for chronic obstructive pulmonary disease (COPD). Cochrane Database Syst Rev. 2013;11:CD009764.

34. Wenzel RP, Fowler AA, Edmond MB. Antibiotic prevention of acute exacerbations of COPD. N Engl J Med. 2012;367(4):340-347.

35. Kew KM, Seniukovich A. Inhaled steroids and risk of pneumonia for chronic obstructive pulmonary disease. Cochrane Database Syst Rev. 2014;3:CD010115.

36. Festic E, Scanlon PD. Incident pneumonia and mortality in patients with chronic obstructive pulmonary disease. A double effect of inhaled corticosteroids? Am J Respir Crit Care Med. 2015;191(2):141-148.

37. Skull SA, Andrews RM, Byrnes GB, et al. ICD-10 codes are a valid tool for identification of pneumonia in hospitalized patients aged $>$ or $=65$ years. Epidemiol Infect. 2008;136:232-240.

38. Drahos J, Vanwormer JJ, Greenlee RT, Landgren O, Koshiol J. Accuracy of ICD-9-CM codes in identifying infections of pneumonia and herpes simplex virus in administrative data. Ann Epidemiol. 2013; 23:291-293.

39. Donaldson GC, Wedzicha JA. COPD exacerbations. 1: Epidemiology. Thorax. 2006;61(2):164-168.

40. Burge S, Wedzicha JA. COPD exacerbations: definitions and classifications. Eur Respir J. 2003;21(Suppl 41):46S-53S.

41. Torres A, Peetermans WE, Viegi G, Blasi F. Risk factors for communityacquired pneumonia in adults in Europe: a literature review. Thorax. 2013;68(11):1057-1165. 


\section{Supplementary materials}

Table SI ICD and ATC classification system codes used in the study

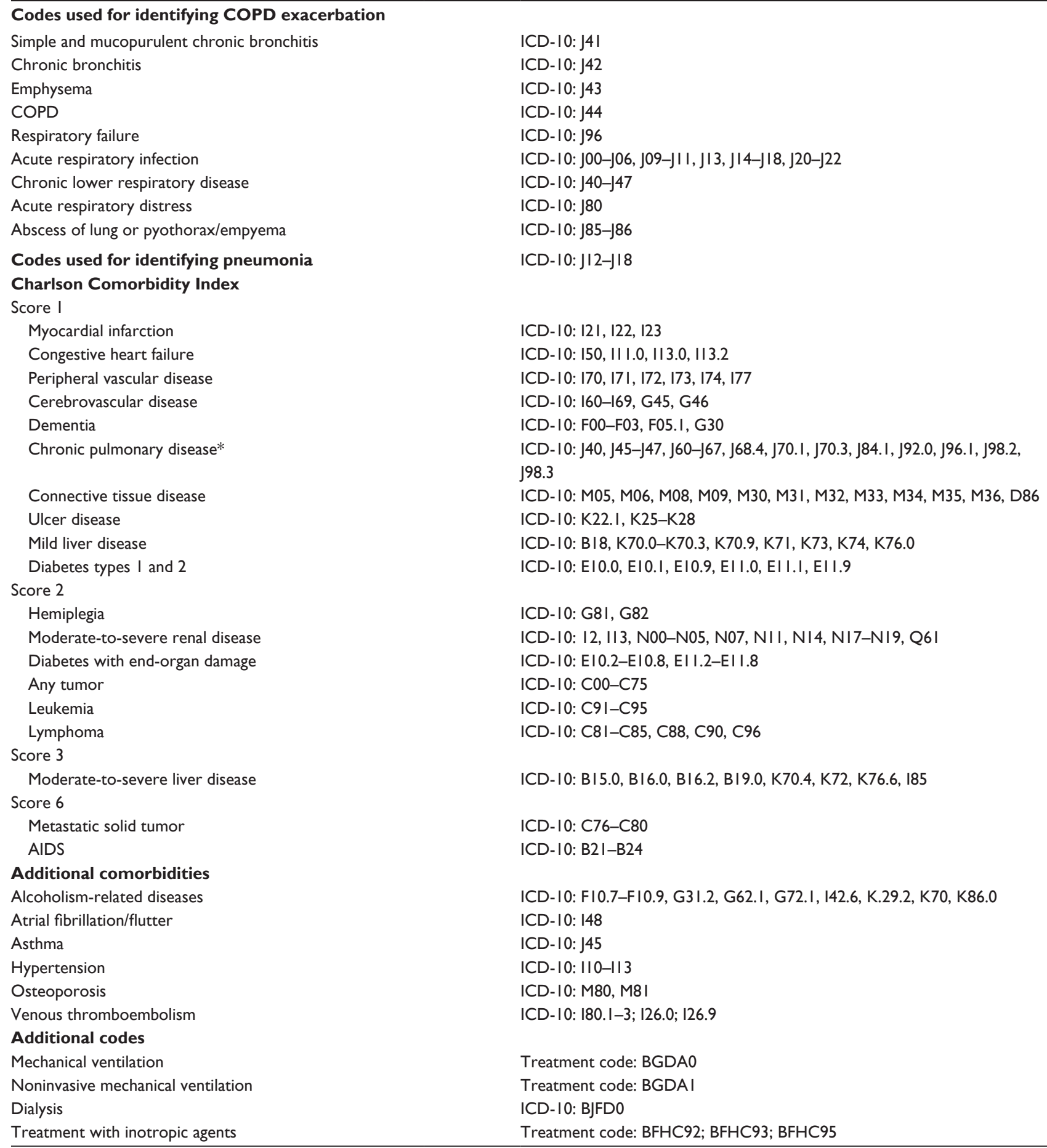


Table SI (Continued)

\section{Respiratory medications}

I) COPD with continuous oral glucocorticoid treatment

2) COPD with oral glucocorticoid treatment

3) COPD with inhaled corticosteroid treatment $\geq$ I prescription for medications with ATC code H02AB group (except injections) 365 days before index date, with medication possession ratio $>0.7$, ie, total number of pills in package(s) covering more than $70 \%$ of the 365 days

$\geq$ I prescription for medications with ATC code H02AB group (except injections) 365 days before index date

$\geq$ I prescription 365 days before index date of inhaled corticosteroids: beclomethasone, mometasone, fluticasone, budesonide (ATC codes R03BA0I, R03BA02, R03BA03, R03BA05, R03BA07), or combinations of inhaled corticosteroids and long acting $\beta$-agonists: salmeterol + fluticasone and formoterol + budesonide (ATC codes R03AK06 and R03AK07, respectively)

$\geq$ I prescriptions for medications with ATC code R03 group other than those in group 3 within 365 days before index date

Note: *Excluding COPD ICD-10: J4I-J44.

Abbreviations: ATC, Anatomical Therapeutic Chemical; COPD, chronic obstructive pulmonary disease; ICD, International classification of diseases.

Table S2 Sensitivity analysis categorizing patients with a discharge diagnosis of "chronic obstructive pulmonary disease with acute lower respiratory infection" (ICD-I0: J44.0) as having a pneumonic COPD exacerbation

\begin{tabular}{|c|c|c|c|c|c|c|c|}
\hline \multirow[t]{2}{*}{$\begin{array}{l}\text { Exacerbation } \\
\text { number }\end{array}$} & \multirow[t]{2}{*}{$\begin{array}{l}\text { Exacerbation } \\
\text { type }\end{array}$} & \multicolumn{3}{|c|}{ Risk of 30-day mortality } & \multicolumn{3}{|c|}{$\begin{array}{l}\text { Risk of a subsequent hospitalization for a COPD } \\
\text { exacerbation }\end{array}$} \\
\hline & & $\begin{array}{l}\text { No of } \\
\text { patients } \\
(\%)\end{array}$ & $\begin{array}{l}\text { 30-day } \\
\text { mortality } \\
(\%)\end{array}$ & $\begin{array}{l}\text { Adjusted } H^{a} \\
(95 \% \mathrm{Cl})\end{array}$ & $\begin{array}{l}\text { Median time to } \\
\text { subsequent } \\
\text { exacerbation } \\
\text { (days) }\end{array}$ & $\begin{array}{l}\text { Proportion with } \\
\text { a subsequent } \\
\text { exacerbation } \\
\text { (\%) }\end{array}$ & $\begin{array}{l}\text { Adjusted } \mathbf{H R}^{\mathrm{a}} \\
(95 \% \mathrm{Cl})\end{array}$ \\
\hline \multirow[t]{2}{*}{ First } & Nonpneumonic & $28,582(54.4)$ & 8.4 & I (reference) & 209 & 42.8 & I (reference) \\
\hline & Pneumonic & $23,938(45.6)$ & 11.3 & $1.15(1.11-1.18)$ & 214 & 39.2 & $0.97(0.94-1.00)$ \\
\hline \multirow[t]{2}{*}{ Second } & Nonpneumonic & $15,928(52.0)$ & 10.5 & I (reference) & $14 \mid$ & 57.9 & I (reference) \\
\hline & Pneumonic & | $4,724(48.0)$ & 13.7 & $1.10(1.07-1.14)$ & 146 & 51.0 & $0.91(0.88-0.94)$ \\
\hline \multirow[t]{2}{*}{ Third } & Nonpneumonic & I I,046 (53.8) & 10.6 & I (reference) & 105 & 65.0 & I (reference) \\
\hline & Pneumonic & $9,483(46.2)$ & 14.0 & $1.12(1.08-1.16)$ & 117 & 58.4 & $0.94(0.91-0.97)$ \\
\hline \multirow[t]{2}{*}{ Fourth } & Nonpneumonic & $8,164(55.8)$ & 10.8 & I (reference) & 82 & 70.0 & I (reference) \\
\hline & Pneumonic & $6,470(44.2)$ & 12.3 & $1.07(I .02-1.11)$ & 94 & 64.0 & $0.90(0.87-0.94)$ \\
\hline \multirow[t]{2}{*}{ Fifth } & Nonpneumonic & $6,308(57.5)$ & 10.7 & I (reference) & 74 & 72.1 & I (reference) \\
\hline & Pneumonic & $4,666(42.5)$ & 12.8 & $1.10(1.04-1.15)$ & 84 & 66.7 & $0.92(0.88-0.97)$ \\
\hline \multirow[t]{2}{*}{ Sixth } & Nonpneumonic & $4,923(58.4)$ & 10.2 & I (reference) & 63 & 75.2 & I (reference) \\
\hline & Pneumonic & $3,503(41.6)$ & 12.4 & I.II (I.05-I.I8) & 74 & 69.7 & $0.92(0.88-0.97)$ \\
\hline Seventh or & Nonpneumonic & $26,4 \mid 4$ (62.9) & 8.7 & I (reference) & 38 & 82.8 & I (reference) \\
\hline greater & Pneumonic & $15,610(3 \mid .7)$ & 10.8 & $1.09(0.07-1.12)$ & 45 & 77.6 & $0.91(0.89-0.93)$ \\
\hline
\end{tabular}

Note: aAjusted for age, sex, $\mathrm{CCl}$ score, and respiratory medications as a marker of COPD severity.

Abbreviations: $\mathrm{Cl}$, confidence interval; $\mathrm{CCl}$, Charlson Comorbidity Index; COPD, chronic obstructive pulmonary disease; HR, hazard ratio.

\section{Publish your work in this journal}

The International Journal of COPD is an international, peer-reviewed journal of therapeutics and pharmacology focusing on concise rapid reporting of clinical studies and reviews in COPD. Special focus is given to the pathophysiological processes underlying the disease, intervention programs, patient focused education, and self management protocols.

\section{Dovepress}

This journal is indexed on PubMed Central, MedLine and CAS. The manuscript management system is completely online and includes a very quick and fair peer-review system, which is all easy to use. Visit $\mathrm{http}: / / \mathrm{www}$. dovepress.com/testimonials.php to read real quotes from published authors. 